\title{
Time temperature equivalence for a mineral filled polymer for automotive applications
}

\author{
Vincent Dorleans ${ }^{1,2, *}$, Franck Lauro ${ }^{1}$, Rémi Delille ${ }^{1}$, Sylvain Treutenaere ${ }^{1}$, Delphine Notta-Cuvier ${ }^{1}$, \\ Bruno Bennani ${ }^{1}$, Grégory Haugou ${ }^{1}$, Benjamin Bourel ${ }^{1}$, Eric Michau ${ }^{2}$, Jean-David Thoby ${ }^{2}$ \\ ${ }^{1}$ University of Valenciennes and Hainaut Cambrésis, LAMIH, UMR CNRS 8201, 59313 Valenciennes \\ ${ }^{2}$ Faurecia Interior System, Méru, France
}

\begin{abstract}
Polymers are currently used in several industrial applications such as the interior components of the vehicle. We find them for example in the design of dashboards or door panels. These materials may be subjected to different types of load like the temperature variation or high strain rates due to crash impact. It is therefore necessary to well understand and to anticipate the complex mechanical behaviour of the polymers. This paper describes the results of experimental research about the dependence between the strain rate and the temperature. The main objective is to be able to model the complete variety of the behaviour in order to predict the risk of failure under dynamic loadings. The material chosen for this study is a copolymer propylene ethylene mineral (talc) filled $15 \%$ impact modified.
\end{abstract}

\section{Introduction}

Automotive industry is a field activity which is subject to constant change. The car manufacturers but also the suppliers always need to adapt to the change of the mentality and the society to propose some new technologies. The well-being, the comfort, the consumption and the safety are the major components in the choice of vehicle. The materials for example have a strong impact in the development of the vehicle parts. For example the polymers have progressively replaced other materials such as the steels thanks to their mechanical properties. They offer the advantage to be more lightweight and usually more ductile in function of additional additives. It is the case for the interior parts of the vehicle such as the dashboards or door panels. The weight reduction became over the years a key issue for the car manufacturers and the suppliers but also the occupant safety. The materials used must meet more and more requirements in terms of safety regulations.

It is then essential to understand the complex behaviour of polymer under a wide range of strain rate and temperature to be able to model the complete range of these behaviours from very ductile to fragile behaviour with the objectives to predict the risk of failure under dynamic loadings. To reach this objective, the first step consists on an experimental characterisation study of a copolymer propylene ethylene mineral (talc) filled $15 \%$ impact modified (used in the design of the top cover) at different temperatures $\left[-30{ }^{\circ} \mathrm{C}\right.$ to $\left.+85^{\circ} \mathrm{C}\right]$ under dynamical loads until $300 \mathrm{~s}^{-1}$.
From the experimental results, a viscoelasticviscoplastic behaviour is observed with a volume variation and damage as well as strong temperature dependence. To cover this wide range of behaviour, the model developed by Balieu $[1,2]$ is used as it allows taking the viscoelasticity-viscoplasticity behaviour with a non associative approach and a non local damage model at room temperature into account. All the parameters of this model are then identified by using direct identification mainly with specific method developed by Epee [3, 4].

In this paper, a focus is also made on the coupling between strain rate and temperature also called "time temperature equivalence". For that, a relation is defined to link these two effects and is introduced into the model of Balieu $[1,2]$ to model the polymer behaviour under a large temperature range.

\section{Material presentation}

The studied material is a copolymer propylene ethylene which is $15 \%$ mineral (talc) filled and impact modified (P/E-MD15 impact modified).

Copolymer propylene ethylene offers semicrystalline structure. The specific compound studied has a block structure which corresponds to the combination of a polypropylene homopolymer and a propylene/ethylene copolymer rich in ethylene (50 to $60 \%$ by weight). In addition, impact modifier ( $\mathrm{E} / \mathrm{P}$ elastomer) was added (Fig.1.). 


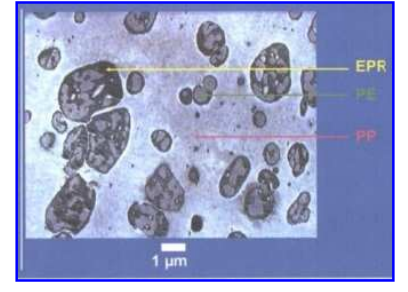

Fig. 1. Morphology of a conventional heterophasic copolymer (EPR: Ethylene Propylene Rubber).

Semi-cristallin polymers show 2 types of transitions:

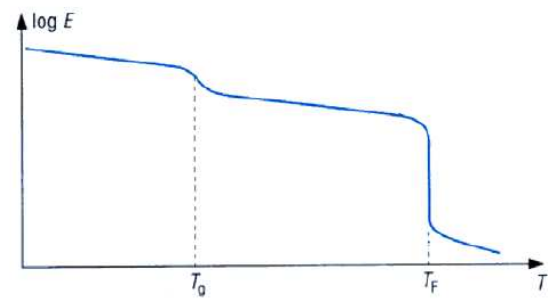

Fig. 2. Transition temperatures for a semi-crystalline [5].

The transition of the amorphous phase, called $\mathrm{T}_{\mathrm{g}}$, marks the passage from the vitreous to the rubbery phase.

Transition from the crystalline phase has all the characteristics of melting: beyond a certain temperature, the polymer behaves like a liquid. This point is therefore known as the melting point, $\mathrm{T}_{\mathrm{f}}$ (Fig.2.).

Here evaluated P/E-MD15 impact modified offers different temperatures of transition due to this complex compound. Indeed it is composed with three glass transition temperatures at $-87.7^{\circ} \mathrm{C}$ (ethylenic phase), at $52.4{ }^{\circ} \mathrm{C}$ (elastomeric phase) and at $+7.8^{\circ} \mathrm{C}$ (propylene phase) as highlighted in (Fig.3.).

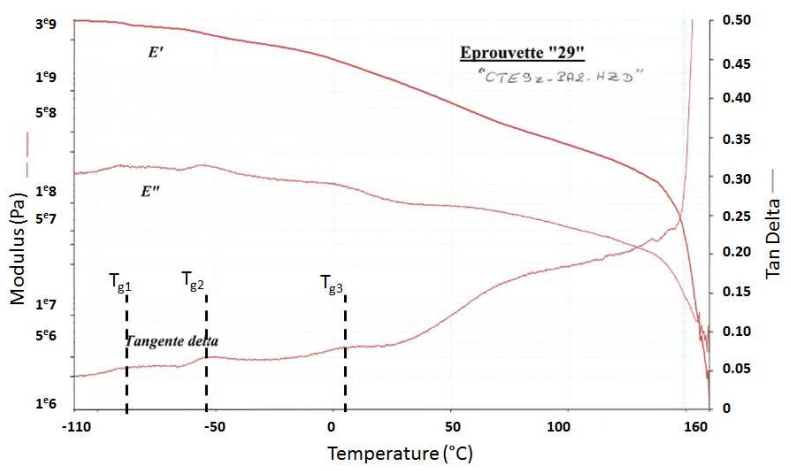

Fig. 3. Storage and loss modulus versus temperature - Heat from $-110^{\circ} \mathrm{C}$ to $180^{\circ} \mathrm{C}$ at $3 \% \mathrm{~min}$.

Endly a talc adjuvant is added in the composition of the material.

Talc is a natural mineral which main composition is Magnesium Silicate Hydrate. Some few quantities of Aluminium, Iron and Calcium Oxydes can be observed (Fig.4.).Depending of its origin, talc color varies from white, beige to grey. It is a very common and used reinforcement inside plastics. Talc particle geometry is lamellar which helps for reducing polymer shrinkage anisotropy and for increasing stiffness and heat resistance. However, addition of talc can strongly reduce polymer impact performance depending of total amount included and particle size [6]. Higher are talc ratio and/or particle size, higher will be the impact performance loss. To counter-balance this drawback, some impact modifier (E/P elastomers) can be included in polymer compound. Talc low hardness through mineral scale generates scratch resistance decrease of final polymer mix.

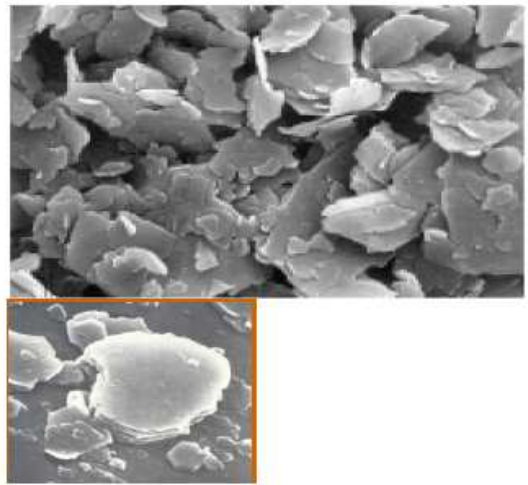

Fig. 4. Talc particles.

Focusing on polypropylene compounds, addition of talc provides several advantages as stiffness increase and better dimensional stability. Such materials are widely used in automotive parts (Ex: under the hood, instrument panels, bumpers...) as well as domestic and electronic appliances or packaging.

Innovative grinding technics are implemented to achieve fine talc quality without destroying lamellar structure which benefits boosting polymer compound performance. Talc is also used as antiblocking agent in polyethylene low linear density (PE-LLD) or nucleating agent into semi-crystalline polymers [7].

\section{Temperature effect}

Usually polymers are very sensitive to different parameters such as the strain rate, the hydrostatic pressure, the compressibility, the temperature and the type of load (tensile/compression/shear). Obviously All the polymers are not sensitive in the same proportions to each one of these parameters. It is thus advisable to treat them from case to case.

As mentioned above, the temperature plays a key role in the behaviour of the polymers but not only, the elastic modulus also. The works performed on the polyamide 6.6 [8] have shown the young modulus strain rate sensitivity. In the frequency range of 0.1 to $100 \mathrm{~Hz}$ for temperatures ranging from $20{ }^{\circ} \mathrm{C}$ to $80{ }^{\circ} \mathrm{C}$, the elastic modulus increases with the frequency at each temperature. However we can notice some significant differences concerning the evolution of the elastic modulus according to the temperature $\left(40 \%\right.$ at $20{ }^{\circ} \mathrm{C}$ and $15 \%$ at $\left.80{ }^{\circ} \mathrm{C}\right)$. Therefore, we can identify a time temperature dependence. We will see whether if this principle can be applied for the P/E-MD15. 


\section{Time temperature superposition}

The time temperature superposition principle is based on the dependence between the strain rate (or the frequency) and the temperature. The elastic modulus so depends on two parameters described below.

$$
\mathrm{E}=\mathrm{f}(\text { time, temperature })
$$

To highlight this dependence, it is necessary to characterize the viscoelastic properties of the material. To achieve this, the dynamic mechanical analysis is the method usually used. At a given frequency range, the storage and loss modulus are measured for different temperatures. The type of graph obtained is shown in the figure 5 .
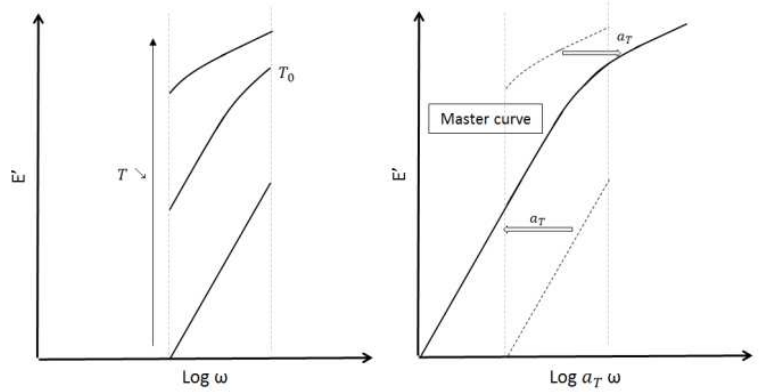

Fig. 5. Frequency sweep for polymer.

A dependence scheme in frequency and temperature can be identified. By using some horizontal shift factors $\mathrm{a}_{\mathrm{T}}$, it is possible to join the different segments. So the master curve obtained will provide the viscoelastic properties of the material on wider frequency range than the initial experimental measurement.

Then it remains to link the temperatures to these coefficients.

In the literature, we can find some equations which allow establishing a relation between the shifted factor and the temperatures. For example, Williams-LandelFerry (WLF) propose the following model.

$$
\log \mathrm{a}_{\mathrm{T}}(\mathrm{T})=\frac{-\mathrm{C}_{1}\left(\mathrm{~T}-\mathrm{T}_{\text {ref }}\right)}{\mathrm{C}_{2}+\left(\mathrm{T}-\mathrm{T}_{\mathrm{ref}}\right)}
$$

In this equation, $\mathrm{T}$ is the current temperature. $\mathrm{T}_{\text {ref }}$ is the reference temperature. $\mathrm{C} 1$ and $\mathrm{C} 2$ are some mathematical constants to identify.

There is also the Vogel law based on the variation of the free volume with the temperature.

$$
\ln \mathrm{a}_{\mathrm{T}}(T)=\frac{-E_{a}}{R}\left(\frac{1}{\left(T-T_{\infty}\right)}-\frac{1}{\left(T_{\text {ref }}-T_{\infty}\right)}\right)
$$

$E_{a}$ is the activation energy. $T_{\infty}$ is the temperature for which the viscosity is infinite.

We can link these two parameters to the two coefficient of the WLF model.

$$
E_{a}=C_{1} C_{2} R \ln (10) \text { and } T_{\infty}=T_{r e f}-C_{2}
$$

Another well-known equation is the Arrhenius equation:

$$
\mathrm{a}_{\mathrm{T}}(\mathrm{T})=\exp \frac{E_{a}}{\mathrm{R}}\left(\frac{1}{\mathrm{~T}}-\frac{1}{\mathrm{~T}_{\mathrm{ref}}}\right)
$$

In this equation, $\mathrm{T}$ is the current temperature, $\mathrm{T}_{\mathrm{ref}}$ is the reference temperature, $\mathrm{E}$ is the activation energy, $\mathrm{R}$ is the gas constant $\left(\mathrm{R}=8.314 \mathrm{~J} / \mathrm{mol}{ }^{\circ} \mathrm{C}\right)$.

Nowadays, the application of the time-temperature superposition for the viscoelastic behaviour has been verified for PA [8, 9], PMMA [10] or PP [11].

Usually the equation of the Williams-Landel-Ferry is used for the amorphous polymers. Concerning the semicrystalline materials, the Arrhenius model is the most suitable [12].

\section{Experiments}

In the context of the study, we will focus on our mineral filled polymer P/E-MD15. The objectif is to characterize the viscoelastic properties in a frequency range between $[0.05$ and $30 \mathrm{~Hz}]$ at different temperatures from $+30{ }^{\circ} \mathrm{C}$ to $+80{ }^{\circ} \mathrm{C}$.

The test device used is a tension/compression machine (Instron Electropulse E3000) with pneumatic grips. It also has a thermo regulated oven ( -100 to 350 ${ }^{\circ} \mathrm{C}$ ). It allows characterizing some materials under different loads (monotonic, alternate, cyclic and DMA) (Fig.7.).

Concerning the test conditions, we apply a sinusoidal signal with amplitude of $0.1 \mathrm{~mm}$ on a sample of rectangular shape $(80 * 10 \mathrm{~mm})$ (Fig.6.). The test carried out is a tensile test.

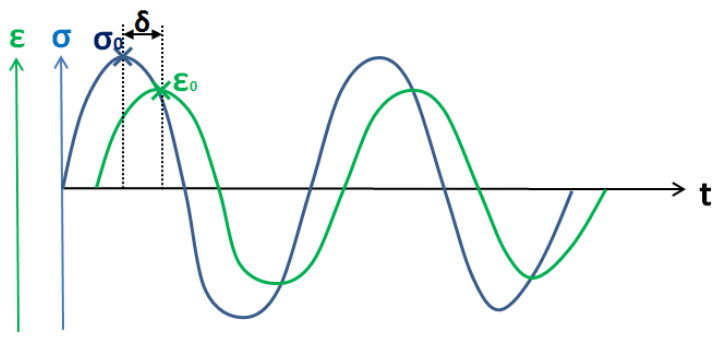

Fig. 6. Input and Output signal of a DMA test.

The storage and loss modulus are calculated as follows:

$$
\begin{aligned}
& \mathrm{E}^{\prime}=\text { Storage Modulus }=\frac{\sigma_{0}}{\varepsilon_{0}} * \cos \delta \\
& \mathrm{E}^{\prime \prime}=\text { Loss Modulus }=\frac{\sigma_{0}}{\varepsilon_{0}} * \sin \delta
\end{aligned}
$$

$\tan \delta=\frac{\mathrm{E} \prime \prime}{\mathrm{E} \prime}=$ Tangent phase angle

$\mathrm{E}^{*}=$ Complex modulus $=\sqrt{\mathrm{E}^{\prime 2}+\mathrm{E}^{\prime \prime 2}}(9)$ 

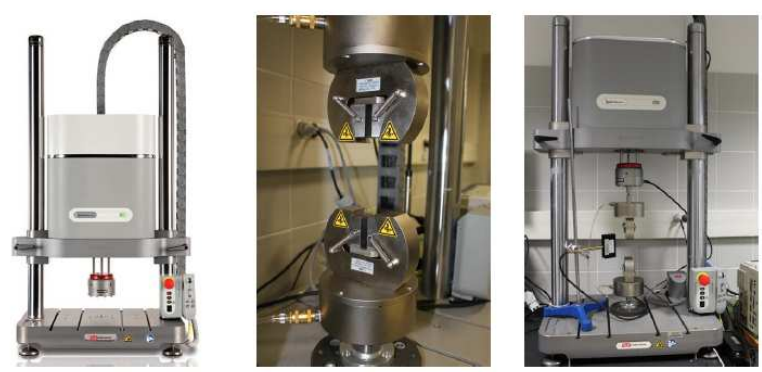

Fig. 7. Test device used for the DMA.

The following figure (Fig.8.) shows the evolution of the storage modulus in function of frequency range [0.05-30 Hz] for various temperatures.

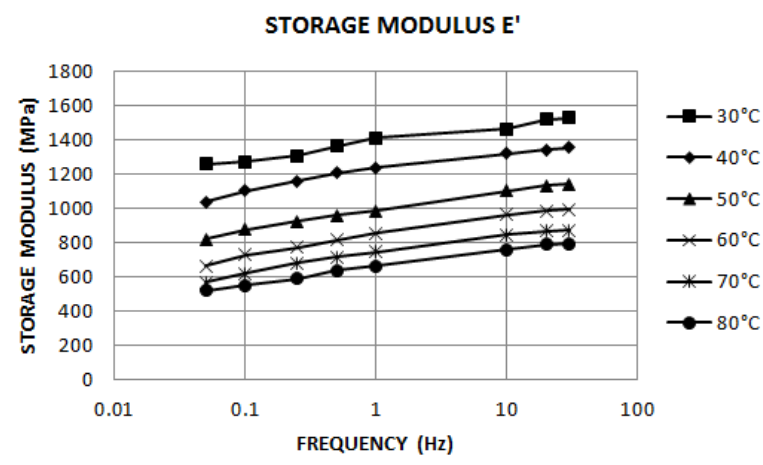

Fig. 8. Storage modulus at different temperatures versus frequency range.

Two observations can be drawn from it. The evolution of the storage modulus is gradual. We notice a gap of $300 \mathrm{MPa}$ for all the temperatures in the frequency range measured. Furthermore the influence of the strain rate on the evolution of the storage modulus is equal whatever the temperature.

From these results, it is now also possible to check if the principle of the time temperature superposition is applicable to our material P/E-MD15 impact modified. To achieve this, first of all, we have fixed the reference temperature to $30^{\circ} \mathrm{C}$ and calculated the different shifted factors for each temperature in order to build a master curve presented on the figure 9 .

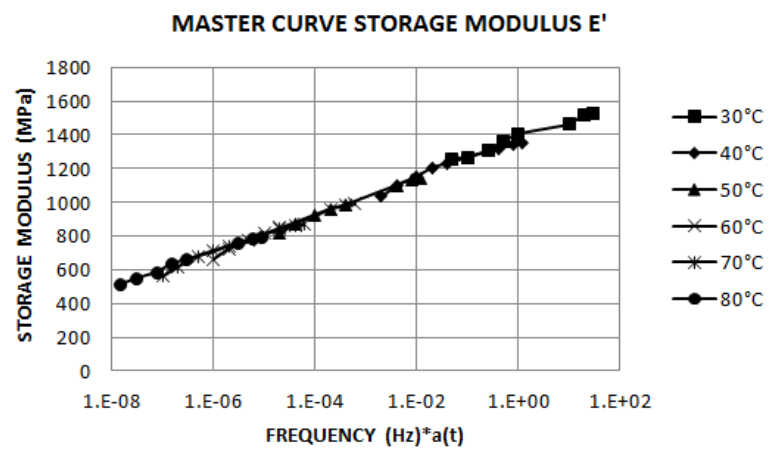

Fig. 9. Storage Modulus of the master curve versus frequency range * shifted factors.
The master curve shows a linear shape in the range of temperature. It is thus easy to establish a relation between the shifted factors and the temperatures. The model chosen is an adaptation of the Arrhenius equation. It is presented in the following form.

$$
a_{T}(\mathrm{~T})=\exp \left(-C\left(T-T_{r e f}\right)\right)
$$

$\mathrm{n}$ this equation, $\mathrm{T}$ is the current temperature. $\mathrm{T}_{\mathrm{ref}}$ is the reference temperature. $\mathrm{C}$ is a mathematical constants to identify. For our material, the constant $\mathrm{C}$ is close to 0.35 . Therefore the principle of the time temperature superposition can be used for the viscoelastic characterization of our material. It allows investigating the complete behavior of the material across a wider frequency range.

In parallel, some tensile tests have been done at different strain rates for two temperatures $23^{\circ} \mathrm{C}$ and $85^{\circ} \mathrm{C}$. The objective is to measure the elastic modulus to compare them with the master curve obtained previously. To estimate the elastic modulus in tensile tests, we use the digital image correlation DIC. The figure (Fig.10.) shows the comparison study and highlighted the good estimation of the time temperature equivalence.

\section{ELASTIC MODULUS}

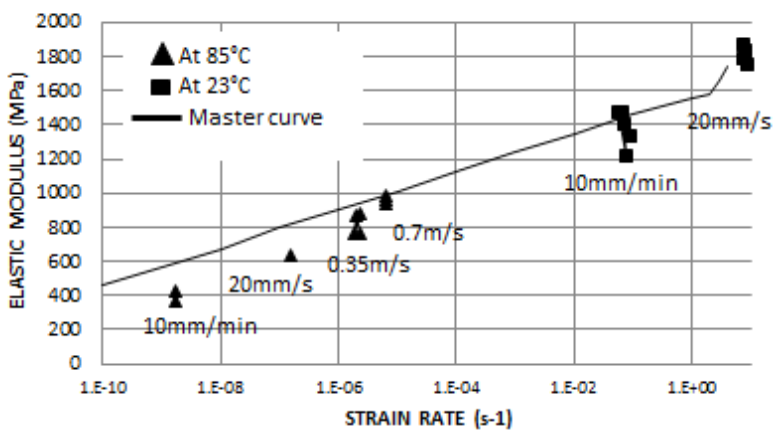

Fig. 10. Evaluation of the elastic modulus from two test methods: DMA and tensile tests.

Overall the two tested methods give some similar results.

The slope looks almost identical. The linear relation between the elastic modulus and the strain rate has been clearly demonstrated.

\section{Concluding remarks}

In this paper, we have shown that the principle of the time temperature superposition is applicable to a mineral filled polymer for the viscoelastic characterization at hot temperatures. The next step is to complete the study by testing at cold temperatures, until $-30{ }^{\circ} \mathrm{C}$, to validate definitively the proposed model (equation (10)).

Some news DMA tests are also planned on another test device completely dedicated this time for DMA applications. The current test device has some functional limitations about the frequency range. It is not possible to exceed $30 \mathrm{~Hz}$. We would like to extend the measure to $100 \mathrm{~Hz}$. 
Endly, it would be now interesting to verify if the time temperature superposition may be applied for the viscoplastic behavior of our material.

The present work has been supported by the LAMIH UMR CNRS 8201, the research department of the University of Valenciennes and the Faurecia Interior System Company. I would like to express my sincere gratitude to all of them.

\section{References}

1. R. Balieu, F. Lauro, B. Bennani, R. Delille, Matsumoto, T., E. Mottola, A fully coupled elastoviscoplastic damage model at finite strains for mineral filled semi-crystalline polymer. International Journal of Plasticity, 51, 241-270 (2013)

2. R. Balieu, F. Lauro, B. Bennani, T. Matsumoto, E. Mottola, Non-associated viscoplasticity coupled with an integral-type non local damage model for mineral filled semi- crystalline polymers. Computers and Structures, 134, 18-31(2014)

3. F. Lauro, B. Bennani, D. Morin., and A. Epee, The SEE method for determination of behaviour laws for strain rate dependant material: Application to polymer material. International Journal of Impact Engineering, 37, 715-722, impact Loading of Lightweight Structures (2010)

4. A. Epee, F. Lauro, B. Bennani, and B. Bourel, Constitutive model for a semi-crystalline polymer under dynamic loading. International Journal of Solids and Structures, 48, 1590-1599 (2011)

5. Précis matières plastiques, J.P. Trotignon \& co., éd. Nathan (1996)
6. Polypropylene, The Definitive User's Guide \& Databook, Clive Maier, Teresa Calafut, PDL (1998)

7. EUROTALC - IMA Europe, Talc Publication

8. E. Baquet, Ph.D. thesis, Modélisation thermomécanique visco-hyperélastique du comportement d'un polymère semi-cristallin : application au cas d'une matrice polyamide 6.6., https://pastel.archivesouvertes.fr/pastel-00715693, Submitted on 9 Jul 2012

9. A. Maurel-Pantel, E. Baquet, J. Bikard, J.-L. Bouvard, and N. Billon, A thermo-mechanical large deformation constitutive model for polymers based on material network description: Application to a semi-crystalline polyamide 66 . International Journal of Plasticity, 67:102-126, 2015

10. N. Billon, New constitutive modeling for timedependent mechanical behavior of polymers close to glass transition: Fundamentals and experimental validation. Journal of Applied Polymer Science, 125(6):4390-4401 (2012)

11. F.-J. Wortmann, K.V. Schulz. Stress relaxation and time/temperature superposition of polypropylene fibres. Polymer Vol. 36 Ko. 2, PP. 315-321 (1995)

12. A. Roncin, Ph.D. thesis, Étude de la modification des propriétés rhéologiques linéaires et non linéaires par ingénierie moléculaire. Vers le contrôle des propriétés adhésives de matériaux autocollants, www.theses.fr. Submitted on 12 Dec 2011. 
